\title{
Retraction Note: Research on comprehensive treatment of water environment in wetland park based on purification and restoration of aquatic plants
}

\author{
Wenjuan Zhou ${ }^{1}$
}

Published online: 6 December 2021

(c) Saudi Society for Geosciences 2021

Retraction Note: Arabian Journal of Geosciences (2021) 14: 995

https://doi.org/10.1007/s12517-021-07203-2

The Editor-in-Chief and the Publisher have retracted this article because the content of this article is nonsensical. The peer review process was not carried out in accordance with the Publisher's peer review policy. The author has not responded to correspondence regarding this retraction.

The original article can be found online at https://doi.org/10.1007/ s12517-021-07203-2.

Wenjuan Zhou

ZWJ8_82020@163.com

1 College of Art Design, Anhui Business College,

Wuhu 241000, Anhui, China 